\title{
Coexistence of Chronic Pain and Depression: A Short Review with a Focus on the Antidepressant Effect of Tramadol and Buprenorphine
}

\author{
Danuta Szkutnik-Fiedler ${ }^{\dagger}$ Edmund Grześkowiak
}

\begin{abstract}
It is known that there is a strong relationship between chronic pain and depression, and both of these diseases can intensify each other. In addition to mental illnesses, there are also a number of somatic symptoms, including pain. While pain, especially chronic, is always associated with mental suffering, which can aggravate the symptoms of depression. Proper and timely identification of coexistence of these conditions allows for effective and safe pharmacotherapy.

This article reviews the literature on the coexistence of chronic pain and depressive disorders. The common mechanisms of both these diseases and the frequency of their coexistence have been described. The results of studies on the problem of treatment of patients with chronic pain with concomitant depression and patients with depression declaring pain are presented. The role of tramadol and buprenorphine in relieving symptoms of depression, including severe and refractory to traditional treatment, has also been described.
\end{abstract}

\section{Keywords}

Pain, Depression, Tramadol, Buprenorphine

\begin{abstract}
Introduction
Chronic pain is a widespread pathology affecting $20 \%-30 \%$ of adults [1]. According to the definition of pain adopted by the International Association for the Study of Pain, pain, regardless of the triggering factor, is always associated with stress and mental suffering, which may intensify the symptoms of depression [1-3].
\end{abstract}

Depression is the most prevalent of all mental illnesses. The oldest depiction of depressive states includes the humorous theory of Hippocrates, who first noted that mental illness is due to natural causes rather than to the supernatural [4]. It is known that depression is characterized by a particularly intense, long-lasting depression in which feelings, apart from mental illnesses, such as: feeling helpless, low self-esteem, constant despair, and loss of feelings, may manifest a number of somatic symptoms including pain, migraines or chronic musculoskeletal pain [512]. Somatic symptoms occur on average in approx. $30-54 \%$ of depressed patients treated in specialized psychiatric centres $[13,14]$. It has been shown that people with depressive disorders have a lowering of the pain threshold and a stronger emotional and cognitive perception of pain, which eventually becomes a chronic pain [15].

The specific consequences of chronic pain in the course of depression (as compared to pain-free

Department of Clinical Pharmacy and Biopharmacy, Poznan University of Medical Sciences, Św. Marii Magdaleny 14, 61-861 Poznań, Poland

${ }^{\dagger}$ Author for correspondence: Danuta Szkutnik-Fiedler, Department of Clinical Pharmacy and Biopharmacy, Poznan University of Medical Sciences, Św. Marii Magdaleny 14, PL 61-861 Poznań, Poland, Tel. +48 61 6687865; Fax: +48 61 6687855; email: d.szkutnik@ wp.pl 
depression) are the longer duration and higher exacerbation of depressive episodes, less efficacy of antidepressants, deterioration in the quality of life, more frequent visits to the physician $[16,17]$. The severity of the depression is proportional to the intensity of the pain experienced [13-17].

Three common symptoms of depression and chronic pain are emotional symptoms (irritability, anxiety, excessive worry, crying, depressive style of thinking, obsessions), somatic symptoms (sleep and appetite disorders, reduced psychomotor efficiency and life energy, impairment of concentration and attention) and symptoms related (guilt, sadness, loss of interest, suicidal tendencies) [1,3]. Therefore, although chronic pain and depression are separate pathological conditions, they often co-exist and affect each other negatively [1827]. This is due, among other things to their common neurobiological component - decreased serotoninergic and noradrenergic activity, increased proinflammatory cytokines and neurotrophins [18]. It is also known that specific limbic brain structures (prefrontal cortex, medial frontal cortex and frontal cortex of the rim of the rim, amygdala, hippocampus) are responsible not only for regulating mood, emotions or memory processes but also for processing impulses associated with the conduction and sensation of pain [3,28-33].

It has also been shown that both in the course of depression and in the case of chronic pain, there are similar changes in activity and blood flow in the brain, especially in the area of the cortex. The role of neuroplasticity in the occurrence and development of chronic pain and depression in the question is not without significance. Neuroplasticity mechanism changes are a potentially significant route for the onset and aggravation of these two diseases $[3,34,35]$. However, the coexistence of pain and depression is not dependent on common anatomical locations. It is also essential to have a common potential genetic background, e.g., the polymorphisms of the catecholamineO-methyltransferase gene are important in susceptibility to depression but are also strongly associated with variability in experimental pain sensitivity [36-40].

\section{Pain Associated with Depression}

Depression may increase the risk of a headache, chest pain and musculoskeletal pain within the next three years after its diagnosis [5]. However, pain complaints reported by patients with depression may not have a somatic background [18]. Chou et al. [6] argue that patients with depression are often diagnosed with headaches or muscle pain, including lower back pain. Comparing the associations of lower back pain, depression, and anxiety with other non-lowerback pains between orthopedic outpatients with chronic low back pain showed that some other pains, such as a headache, chest pain, and general muscle pain, appeared to be more strongly associated with depression than with the pain intensity of low back pain. The results of a meta-analysis by Bair et al. [19] indicate that the frequency of pain reporting in psychiatric patients varies from $15 \%$ to even $100 \%$ (on average $65 \%$ ).

It has been shown that in patients hospitalized for major depression, at least one symptom of pain (e.g., a headache, back pain, abdominal pain or musculoskeletal pain) was reported by $92 \%$ of respondents, and $76 \%$ with many painful ailments. Men more often declare muscular pains and women report headaches and chest pain [41]. Pain may also occur in patients with less severe depressive disorders such as dysthymia, bipolar affective disorder, minor depression, or incomplete remission in severe depression [42]. In primary care, pain is declared by nearly $70 \%$ of depressed patients, compared to $38.6 \%$ of patients without depression [43]. In the meta-analysis conducted by Agürer-Ortiz et al. [15], it was found that in 3566 adult patients with depressive disorders, pain occurred in 59\% of subjects, more frequently in women than in men and more often in patients $>50$ years of age. The pain most often concerned the back area and the sacral area. Researchers have shown that depression has a significant impact on pain perception, regardless of the existence of pain stimuli. Ohayon and Schatzberg's study [44] on a group of 18,980 people aged 15 to 100 showed that $43.4 \%$ had at least one type of pain, showed an episode of depression in $4 \%$.

\section{- Depression and painful symptoms}

Depression is seen in about $50 \%$ of patients with chronic pain $[3,5,8,24]$. Major depression occurs in $53 \%$ of patients in pain clinics, $38 \%$ in psychiatric clinics, $56 \%$ in orthopedic and rheumatology clinics, $85 \%$ in dental clinics dealing with craniofacial pain and $13 \%$ in gynecological clinics. Patients with at least two pain ailments are 6 to 8 times more likely to develop depression. Patients who have been in pain for over six months have also been reported 
to suffer from depression four times more often than patients not reporting chronic pain [5].

Wasilewski et al. [5] in an epidemiological study on the population of mental health and neurological clinics in Poland (3726 women and 2116 men), showed a statistically significant relationship between the severity of pain and depression, anxiety, as well as suicidal thoughts. Patients with more severe depression and anxiety symptoms also have an increase of pain problems.

It has been shown that depression is not diagnosed in approximately $50 \%$ of cases reported to doctors due to somatic symptoms accompanying depressive disorders. This is a significant problem because pain is the first symptom of depression $[5,15,42]$.

In patients with malignant neoplasia with severe pain, the risk of depression is more than double that of patients with less severe pain. However, the risk of depression in cancer cases can often be independent of the presence of pain [45].

In the case of advanced rheumatic diseases, depression may occur in $68 \%$ of patients, $22 \%$ are symptomatic of the development of depressive disorders $[45,46]$. However, the results of studies in young patients aged 14 to 20 hospitalized for rheumatic or neoplastic disease indicate that only $7 \%$ of patients with arthritis and $9 \%$ of patients with cancer have depression. This may be due to, among other reasons, patients hiding the symptoms of the depressive disorder. Also, the severity of the above conditions in these patients was quite low. However, it was shown that with the increase in the degree of pain experienced, the number of reported symptoms of depressive disorders increased [45].

Depression is also very common in patients with migraines (approximately 57\%) and patients with tension headaches (51\%) [5,7,9,11,12,4758]. Psychiatric comorbidities are more common among persons with a chronic migraine than among those with episodic migraines [11]. Jette et al. [52] in a study on a group of 36,984 migraine sufferers showed that migraine is associated with the major depressive disorder, bipolar disorder, panic disorder, and social phobia which results in poorer health-related outcomes compared with migraine or a psychiatric condition alone. Molgat and Patten [54] showed a strong correlation between the incidence of severe depression and migraine in a study of the Canadian population (over 130,000 sample). Patients with migraine are 2-4 times more likely to develop lifetime major depressive disorder, predominantly due to similar underlying pathophysiologic and genetic mechanisms $[47,48,53,58]$. Also, psychiatric comorbidities may be a risk factor for migraine chronification (i.e., progression from episodic to a chronic migraine) [11] and many migraine patients with depression are inadequately treated [12].

\section{- Treatment of depression}

The simultaneous occurrence of pain and depression requires proper pharmacotherapy to alleviate both pain and depressive disorders. Polypharmacotherapy carries a risk of drug interactions that are dangerous for health and life. Numerous clinical studies have demonstrated that most of the currently used antidepressants also have pain-relieving effects, especially tricyclic antidepressants (TCA) and serotonin-norepinephrine reuptake inhibitors (SNRIs). In addition, mirtazapine and mianserin are also used $[59,60]$. It is believed that these drugs, compared to selective serotonin reuptake inhibitors (SSRIs), exhibit higher independent depressive symptoms, analgesic efficacy in such pain syndromes as diabetic neuropathy, fibromyalgia and tension and migraine headaches [60-63].

SNRIs such as serotonin and noradrenaline reuptake inhibitors suppress nociception at the level of the spinal cord, inhibit sodium channels and activation processes of $\mathrm{N}$-methylD-aspartate (NMDA) receptors, demonstrating the synergy of action with opioid analgesics [60]. In addition to the potential of opioid analgesia, they also cause a reduction in muscle tone and anxiolytics [60,62-64]. However, studies by Jaracz et al. [65] indicate the similar efficacy of SNRI and SSRI in relieving unexplained painful physical symptoms associated with depression. In patients with severe depression, comparable analgesic efficacy has been demonstrated for venlafaxine, escitalopram, and nortriptyline [66]. From the SNRI group, venlafaxine and duloxetine are often used in practice. These drugs are effective in the treatment of peripheral neuropathic pain, in the treatment of low back pain, shoulder pain, and fibromyalgia [67-70].

\section{Opioids in Treating Depression}

\section{- Buprenorphine and its new analogues}

Clinical and pre-clinical studies have demonstrated the efficacy of buprenorphine and its novel analogues in the pharmacotherapy 
of depression [3,71-76]. Ahmadi et al. [73] suggest that a single high-dose of buprenorphine provides a safe, speedy and straightforward means of depression, especially in patients who are opioid dependent. Due to the knowledge that the $\kappa$ receptor antagonists have the potential for treating neuropsychiatric disorders, Almatroudi et al. [74] investigated the pharmacology of a novel buprenorphine analogue, BU10119 in CD1 mice. BU10119 is a mixed $\kappa / \mu$ receptor antagonist with relatively short-duration $\kappa$ antagonist activity. It was shown that this buprenorphine analogue has therapeutic potential for the treatment of depression and other stress-induced conditions. Almatroudi et al. [75] also showed that co-administration of buprenorphine with naltrexone in CD-1 mice produced an antidepressant-like response in behaviours in both the forced swim test and novelty-induced hypophagia task what means that this combination represents a novel approach, to the treatment of depression. According to a study by Karp et al. [71], buprenorphine provides rapid and sustained improvement for older adults with treatment-resistant depression. A low-dose of buprenorphine sharply decreased major depression severity during the first three weeks of treatment. Side effects, like nausea and constipation, were not sustained. Vital signs and weight were stable, and the executive function and learning improved. Fava et al. [72] studied the antidepressant activity of a combination of buprenorphine and a $\mu$-opioid antagonist, samidorphan in patients with major depression. They showed significantly greater antidepressant effects for this combination compared to the placebo and concluded that it might be a promising candidate for the treatment of a major depressive disorder in patients who have an inadequate response to standard antidepressants.

\section{- Tramadol}

Regarding chemical structure and mechanism of action, tramadol (2- (dimethyl aminomethyl) -1- (3-methoxyphenyl) cyclohexane-1-ol hydrochloride) is similar to venlafaxine [77]. Tramadol is also a serotonin and norepinephrine reuptake inhibitor has antidepressant action, which has been proven in numerous preclinical studies [77-85] and clinical observations [78]. The tramadol anti-depressant effect can be translated, e.g., in that this opioid increases the density of $\alpha_{1}$-adrenoreceptors and decreases the density of $\alpha_{2}$-adrenoreceptors [79-82], causes up-regulation of dopamine D2 and D3 receptors in the rat nucleus accumbens [79] and interacts with the imidazoline $\mathrm{I}_{2}$ receptors [86]. Also, the ability of tramadol to modulate opioid receptors [87], its impact on the serotonergic system $[80,84]$, and on L-arginine-nitric oxide-cyclic guanosine monophosphate pathway [80] and potassium channels [88] is not insignificant. Our studies have also shown that combination of a low-dose of tramadol $(5 \mathrm{mg} / \mathrm{kg})$ with venlafaxine caused an increased antidepressant effect compared to tramadol and venlafaxine administered alone, with no effect on locomotor activity or motor coordination in rats [77]. We have also shown that tramadol improves spatial memory in rats [89], as evidenced in the literature [90-94]. The results of studies carried out by Mintzer et al. [93] indicate, for example, that tramadol administered in large doses (up to $800 \mathrm{mg}$ per day) compared to morphine has a positive effect on cognitive functions in opioid addicts. It has also been shown that the use of tramadol in patients with chronic non-cancer pain may improve cognitive function in patients [95]. Moreover, tramadol improves memory functions in healthy volunteers [96], recreational drug users [90], post-operative patients [92] and patients with catatonia [78,94]. However, Bassiony et al. [97] demonstrated that cognitive, including memory, impairment occurs commonly among tramadol-abuse patients and there was a significant association between cognitive impairment and polysubstance abuse.

\section{- Long-term use of tramadol and buprenorphine in relieving symptoms of depression}

It is known that long-term use of opioids, especially in high doses, may lead to addiction, physical dependence, withdrawal syndrome, and tolerance. Chronic pain and depression or stress facilitate addiction in that they result in maladaptive disruptions to the body's neuronal and hormonal system, that in turn, can affect the mesolimbic dopaminergic pathways. Therefore, chronic pain itself may set the stage to make a patient more likely to perceive opioids as rewarding and thus addictive [98]. However, in the case of tramadol [98-100] and buprenorphine $[98,101]$ the risk of addiction might be lower than other opioids.

In case of tramadol addiction and withdrawal symptoms appear more frequently when using this drug in high doses. It seems that tramadol-dependence dose is more important than duration of use [99]. Tramadol may also have a relatively lower potential for abuse than 
single-mechanism pure opioids because its dual mechanism of action (opioid and non-opioid) deliver contradictory messages to the brain concerning reward [98].

Buprenorphine is a partial agonist at the $\mu$ opioid receptor and an antagonist at the $\kappa$ receptor, and has a good affinity for the $\delta$ opioid receptor [3,71]. The lower abuse potential of buprenorphine is consistent with its partial agonist effects and the resultant ceiling on maximal results produced. Due to these facts, buprenorphine also has a lower level of physical dependence (less withdrawal discomfort) and greater safety in overdose compared with opioid full agonists. Moreover, buprenorphine's pharmacological and safety profile makes it an attractive treatment for patients addicted to opioids because may displace opioid full agonists from the opioid receptors $[98,101]$.

Several studies have also shown that tramadol $[77,78,80]$ and buprenorphine [71,101] have an antidepressant effect even at low doses, which may reduce the risk of addiction.

So, it seems, that long-term consumption of low doses of tramadol or buprenorphine in relieving symptoms of depression should lead to addiction to a lesser degree than do other opioids.

- The role of tramadol and buprenorphine in the inactivation of cycle pain-depression

It has to be noted that depression may prolong the duration of opioid consumption and the long-term use of opioids has been shown to increase the risk of depression [3,100]. All three standard types of opioid receptors $\mu, \kappa$ and $\delta$ are involved in regulating $\operatorname{mood}[1,3]$. The occurrence and development of depression include many neurotransmitter systems that are associated with changes in neuroplasticity. The opioid receptors may achieve antidepressant effects by regulating these neurotransmitter systems, e.g., the $\mu$ receptor - by controlling the activity of serotonin neurons, and the $\kappa$ receptor - by directly inhibiting the release of dopamine. The $\delta$ receptor-knockout mice exhibit increased depressive-like behaviors, so this receptor may also be a potential antidepressant target [3]. Due to the mechanisms of action of tramadol [77-97] and buprenorphine [71-76], it may be concluded, that both drugs may enhance synaptic plasticity and achieve the purpose of antidepressant therapy by adjusting neurotransmitter systems [3].
Therefore, the treatment by tramadol or buprenorphine in relieving symptoms of depression may be involved in the inactivation of cycle pain-depression.

\section{- Neurodegeneration as the primary defect in the induction of depression and chronic pain cycle}

It was documented that frontal-limbic dysfunction may be considered as a common factor for both depression and chronic pain and the pattern of activation of brain structures involved in pain processing seems to be abnormal in depression [18].

Neurodegeneration may specifically involve the somatosensory system, thus making a neuropathic origin of pain, or it may affect cortical and subcortical structures of the brain involved in pain modulation [102]. Dellarole et al. [103] showed a temporal relationship between neuropathic pain and the occurrence of depressive-like symptoms as well as structural neuroplastic and white matter impairments of the hippocampus. They hypothesized that chronic neuropathic pain-induced depression might be dependent on hippocampal tumor necrosis factor (TNF) through TNF receptor 1 (TNFR1) and is associated with different forms of hippocampal changes such as reduced neurogenesis, neuronal plasticity, and myelin remodeling. Other neuroplastic changes such as reduced spine density and dendritic retraction, were also described in animal models of depression or pain [103].

Therefore, it can be stated, that neurodegeneration is the primary defect in the induction of depression and chronic pain cycle of intensification.

\section{- Tramadol and buprenorphine for the treatment of neurodegenerative diseases that involve depression and chronic pain}

Due to the pharmacological properties of tramadol and buprenorphine described above, these opioids seem to be useful for the treatment of pain and depression in patients with neurodegenerative diseases. It was also demonstrated that buprenorphine treatment leads to an improvement in regional cerebral perfusion abnormalities [104,105], while tramadol significantly attenuates behavioral, biochemical, mitochondrial and histological alterations in animal studies (intracerebroventricular-streptozocin sporadic dementia of Alzheimer's type Wistar rats) [106]. 
It might suggest the neuroprotective potential of these opioids.

Tramadol is recommended as a second-line treatment of neuropathic pain which is one of the most common types of pain in patients with neurodegenerative diseases [107].

However, intoxications due to opioids are very common, and in many cases, toxic mechanisms of drugs are not fully understood. It should be taken into consideration that some animal studies have shown that chronic use of tramadol in increasing doses may be associated with neuronal degeneration in the brain and finally cerebral dysfunction. Faria et al. [108] showed for example that exposure to tramadol might cause brain injury, evidenced by the increased lactate levels, and histological damage, namely swollen neurons, poorly defined nuclear membranes and neuronal death.

\section{- Tramadol and buprenorphine as effective pharmacotherapy with relevance to other drugs consumed with chronic pain and depression}

It seems that the use of tramadol and buprenorphineinvolveeffective pharmacotherapy with relevance to other drugs consumed with chronic pain and depression. It can be due to their antidepressant activity, less risk of addiction and physical dependence, as was described above. Moreover, buprenorphine's pharmacokinetics is not influenced by age, and renal function [3] and this opioid may be successfully used in the treatment of opioid addiction [101]. While tramadol also has anti-inflammatory activity and is useful in the treatment of neuropathic pain $[87,107]$.

However, extensive using of these drugs in the treatment of chronic pain-induced depression should be further studied.

\section{Conclusion}

In conclusion, in addition to the range of anti-depressants with an analgesic effect, the results of research on the possibility of using buprenorphine or tramadol in the treatment of patients with chronic pain and coexisting depression seem promising.

It should be borne in mind that there is a strong relationship between these two diseases, which may intensify each other. This is due, among other things, to similar biochemical mechanisms and to the fact that the same areas of the central nervous system are responsible for the feeling of pain and depression. Correct diagnosis of the coexistence of these conditions, i.e., a prematurely diagnosed depression in a patient with chronic pain, and not ignoring the pain in a depressed patient, can lead to an effective and safe pharmacotherapy of both disorders.

\section{Competing Interests}

The authors declared that they had no competing interests.

\section{References}

1. Abdallah CG, Geha P. Chronic Pain and Chronic Stress: Two Sides of the Same Coin? Chronic. stress (2017).

2. Fornasari D. Pharmacotherapy for Neuropathic Pain: A Review. Pain. Ther 6(1), 25-33 (2017)

3. Sheng J, Liu S, Wang Y, et al. The Link between Depression and Chronic Pain: Neural Mechanisms in the Brain. Neural. Plast 9724371 (2017).

4. Durà-Vilà D, Littlewood R, Leavey G. Depression and the medicalization of sadness: conceptualization and recommended help-seeking. Int. J. Soc. Psychiatry 59(2), 165-175 (2013).

5. Wasilewski D, Wojnar M, Chatizow J. Depression and pain: polish epidemiologic study. Psychiatr. Pol 44(3), 436-445 (2010).

6. Chou YH, Fu TS, Hung Cl. Depression: An Important Factor Related to Other Pains among Patients with Chronic Low Back Pain. Neuropsychiatry (London) 7(5), 651658 (2017).

7. Hung $\mathrm{Cl}$, Liu CY, Chen CY, et al. The impacts of migraine and anxiety disorders on painful physical symptoms among patients with major depressive disorder. J. Headache. Pain 15(1), 73 (2014).

8. Hung $\mathrm{Cl}$, Liu CY, Fu TS. Depression: an important factor associated with disability among patients with chronic low back pain. Int. J. Psychiatry. Med 49(3), 187-198 (2015).

9. Ligthart L, Gerrits MM, Boomsma DI, et al. Anxiety and depression are associated with migraine and pain in general: an investigation of the interrelationships. J. Pain 14(4), 363-370 (2013).

10. Crofford, LJ. Psychological aspects of chronic musculoskeletal pain. Best. Pract. Res. Clin. Rheumatol 29(1), 147-155 (2015).

11. Buse DC, Silberstein SD, Manack AN, et al. Psychiatric comorbidities of episodic and chronic migraine. J. Neurol 260(8), 19601969 (2013).

12. Amoozegar F. Depression comorbidity in migraine. Int. Rev. Psychiatry 29(5), 504-515 (2017).

13. Lee $P$, Zhang $M$, Hong JP, et al. Frequency of painful physical symptoms with major depressive disorder in Asia: relationship with disease severity and quality of life. J. Clin. Psychiatry 70(1), 83-91 (2009).

14. Bahk WM, Park S, Jon DI, et al. Relationship between painful physical symptoms and severity of depressive symptomatology and suicidality. Psychiatry. Res 189(3), 357-61 (2011).

15. Agüera-Ortiz L, Failde I, Mico JA, et al. Pain as a symptom of depression: prevalence and clinical correlates in patients attending psychiatric clinics. J. Affect. Disord 130(1-2), 106-112 (2011).

16. Vadivelu N, Kai AM, Kodumudi G, et al. Pain and Psychology-A Reciprocal Relationship. 
Coexistence of Chronic Pain and Depression: A Short Review with a Focus on the Antidepressant Effect of RevieW Tramadol and Buprenorphine

Ochsner. J 17(2), 173-180 (2017).

17. Sambamoorthi U, Shah D, Zhao X. Healthcare burden of depression in adults with arthritis. Expert. Rev. Pharmacoecon. Outcomes. Res 17(1), 53-65 (2017).

18. Jaracz J, Gattner K, Jaracz K. Unexplained Painful Physical Symptoms in Patients with Major Depressive Disorder: Prevalence, Pathophysiology and Management. CNS. Drugs 30(4), 293-304 (2016).

19. Bair MJ, Robinson RL, Katon W, et al. Depression and pain comorbidity: a literature review. Arch. Intern. Med 163(20), 2433-45 (2003).

20. Cocksedge KA, Simon C, Shankar R. A difficult combination: chronic physical illness, depression, and pain. Br. J. Gen. Pract 64(626), 440-441 (2014).

21. Pereira FG, Franca MH, Paiva MCA, et al. Prevalence and clinical profile of chronic pain and its association with mental disorders. Rev. Saude Publica 51(1), 96 (2017).

22. Husain MM, Rush AJ, Trivedi MH, et al. Pain in depression: STAR*D study findings. $J$. Psychosom. Res 63(2), 113-22 (2007).

23. Demyttenaere K, Reed C, Quail D, et al. Presence and predictors of pain in depression: results from the FINDER study. J. Affect. Disord 125(1-3), 53-60 (2010).

24. Robinson KM, Monsivais JJ. Depression, Depressive Somatic or Nonsomatic Symptoms, and Function in a Primarily Hispanic Chronic Pain Population. ISRN. Pain 2013, 401732 (2012).

25. Nicholl BI, Mackay D, Cullen B, et al. Chronic multisite pain in major depression and bipolar disorder: cross-sectional study of 149,611 participants in UK Biobank. BMC. Psychiatry 14(1), 350 (2014).

26. de Heer EW, Gerrits MMJG, Beekman ATF, et al. The association of depression and anxiety with pain: a study from NESDA. PLoS. One 9(10), e106907 (2014).

27. Gerrits MM, Vogelzangs N, van Oppen P, et al. Impact of pain on the course of depressive and anxiety disorders. Pain 153(2), 429-36 (2012).

28. Kregel J, Coppieters I, DePauw R, et al. Does Conservative Treatment Change the Brain in Patients with Chronic Musculoskeletal Pain? A Systematic Review. Pain. Physician 20(3), 139154 (2017)

29. Lenoir C, Huang G, Vandermeeren Y. Human primary somatosensory cortex is differentially involved in vibrotaction and nociception. $J$. Neurophysiol 118(1), 317-330 (2017).

30. Laine MA, Sokolowska E, Dudek M, et al. Brain activation induced by chronic psychosocial stress in mice. Sci. Rep 7(1), 15061 (2017).

31. Gagliese L, Gauthier LR, Narain N, et al. Pain, aging and dementia: Towards a biopsychosocial model. Prog. Neuropsychopharmacol. Biol. Psychiatry pii: S0278-5846(17)30383-4 (2017).

32. Meerwijk EL, Ford JM, Weiss SJ. Brain regions associated with psychological pain: implications for a neural network and its relationship to physical pain. Brain. Imaging. Behav 7(1), 1-14 (2013).

33. Baliki MN, Petre B, Torbey S. Corticostriatal functional connectivity predicts transition to chronic back pain. Nat. Neurosci 15(8), 11171119 (2012).

34. Li X, Hu L. The role of stress regulation on neural plasticity in pain chronification. Neural. Plast 6402942 (2016).

35. Li XY, Wan Y, Tang SJ, et al. Maladaptive plasticity and neuropathic pain. Neural. Plast 4842159 (2016).

36. Ciszek BP, O’Buckley SC, Nackley AG. Persistent Catechol-O-methyltransferasedependent Pain Is Initiated by Peripheral $\beta$-Adrenergic Receptors. Anesthesiology 124(5), 1122-35 (2016).

37. Kline RH 4th, Exposto FG, O'Buckley SC, et al. Catechol-O-methyltransferase inhibition alters pain and anxiety-related volitional behaviors through activation of $\beta$-adrenergic receptors in the rat. Neuroscience 290(1), 561 569 (2015).

38. Patanwala IY, Lamvu G, Ledger WJ, et al. Catechol-O-methyltransferase gene polymorphism and vulvar pain in women with vulvodynia. Am. J. Obstet. Gynecol 216(4), 395.e1-395.e6 (2017).

39. Ablin JN, Buskila D. Update on the genetics of the fibromyalgia syndrome. Best Pract. Res. Clin. Rheumatol 29(1), 20-28 (2015).

40. Bastos P, Gomes T, Ribeiro L. CatecholO-Methyltransferase (COMT): An Update on Its Role in Cancer, Neurological and Cardiovascular Diseases. Rev. Physiol. Biochem. Pharmacol 173(1), 1-39 (2017).

41. Corruble E, Guelfi JD. Pain complaints in depressed inpatients. Psychopathology 33(6), 307-309 (2000).

42. Agüera L, Failde I, Cervilla JA, et al. Medically unexplained pain complaints are associated with underlying unrecognized mood disorders in primary care. BMC Fam. Pract 11(1), 17 (2010).

43. Gameroff MJ, Olfson M. Major depressive disorder, somatic pain, and health care costs in an urban primary care practice. J. Clin. Psychiatry 67(8), 1232-1239 (2006).

44. Ohayon MM, Schatzberg AF. Using chronic pain to predict depressive morbidity in the general population. Arch. Gen. Psychiatry 60(1), 39-47 (2003).

45. Cepuch G, Wordliczek J. Assessment of relation between pain intensity and fear and depression occurrence in adolescents hospitalized because of cancer and rheumatoid diseases. Palliative. Medicine 5(2), 44-53(2006).

46. Szkutnik-Fiedler D, Grześkowiak E, Wyrowski Ł. Chronic pain and depression. Farm. Wsp 7(1), 1-4 (2014).

47. Amoozegar F, Patten SB, Becker WJ, et al. The prevalence of depression and the accuracy of depression screening tools in migraine patients. Gen Hosp. Psychiatry 48(1), 25-31 (2017).

48. Amoozegar F. Depression comorbidity in migraine. Int. Rev. Psychiatry 29(5), 504-515 (2017).

49. Antonaci F, Nappi G, Galli F, et al. Migraine and psychiatric comorbidity: A review of clinical findings. J. Headache. Pain 12(2), 115125 (2011).

50. Baskin SM, Smitherman TA. Migraine and psychiatric disorders: comorbidities, mechanisms, and clinical applications. Neurol. Sci 30(1), S61-S65 (2009).

51. Gudmundsson LS, Scher Al, Sigurdsson S, et al. Migraine, depression, and brain volume: The AGES-Reykjavik study. Neurology 80(23), 2138-2144 (2013).

52. Jette N, Patten S, Williams J, et al. Comorbidity of migraine and psychiatric disorders: $A$ national population-based study. Headache 48(4), 501-516 (2008).

53. Lighthart L, Hottenga JJ, Lewis CM, et al. Genetic risk score analysis indicates migraine with and without comorbid depression are genetically different disorders. Hum. Genet 133(2), 173-186 (2014).

54. Molgat CV, Patten SB. Comorbidity of major depression and migraine-a Canadian population-based study. Can. J. Psychiatry 50(13), 832-837 (2005).

55. Nguyen TV, Low NC. Comorbidity of migraine and mood episodes in a nationally representative population-based sample. Headache 53(3), 498-506 (2013).

56. Oedegaard KJ, Neckelmann D, Mykletun $\mathrm{A}$, et al. Migraine with and without aura: Association with depression and anxiety disorder in a population-based study. The HUNT study. Cephalalgia 26(1), 1-6 (2006).

57. Tietjen GE, Brandes JL, Digre KB, et al. High prevalence of somatic symptoms and depression in women with disabling chronic headache. Neurology 68(2), 134-140 (2007).

58. Yang Y, Ligthart L, Terwindt GM, et al. Genetic epidemiology of migraine and depression. Cephalalgia 36(7), 679-691 (2016).

59. Mehta S, Guy S, Lam T, et al. Antidepressants Are Effective in Decreasing Neuropathic Pain After SCI: A Meta-Analysis. Top. Spinal. Cord. 


\author{
Inj. Rehabil 21(2), 166-173 (2015).
}

60. Woroń J, Adamczyk A, Malec-Milewska M, et al. The use of analgesics in patients with neuropathic pain in the course of cancer. Medycyna Paliatywna w Praktyce. 8, 2, 85-90 (2014).

61. Widerström-Noga E. Neuropathic Pain and Spinal Cord Injury: Phenotypes and Pharmacological Management. Drugs 77(9), 967-984 (2017)

62. Dworkin RH, O'Connor AB, Audette J, et al. Recommendations for the pharmacological management of neuropathic pain: An overview and literature update. Mayo. Clin. Proc 85(1), S3-S14 (2010).

63. Hajak G. Dual acting reuptake inhibitors in the treatment of depression and pain. Dtsch. Med. Wochenschr 131(8), S280-S283 (2006).

64. Jann MW, Slade JH. Antidepressant agents for the treatment of chronic pain and depression. Pharmacotherapy 27(11), 15711187 (2007).

65. Jaracz J, Gattner K, Moczko J, et al. Comparison of the effects of escitalopram and nortriptyline on painful symptoms in patients with major depression. Gen. Hosp. Psychiatry 37(1), 36-39 (2015).

66. Jaracz J, Gattner K, Jaracz K, et al. Is Venlafaxine More Effective than Escitalopram and Nortriptyline in the Management of Painful Symptoms in Patients with Major Depression? Pharmacopsychiatry (2017).

67. Ito S, Suto T, Saito S, et al. Repeated Administration of Duloxetine Suppresses Neuropathic Pain by Accumulating Effects of Noradrenaline in the Spinal Cord. Anesth. Analg (2017).

68. Ogawa K, Fujikoshi S, Montgomery W, et al. Correlation between pain response and improvements in patient-reported outcomes and health-related quality of life in duloxetine-treated patients with diabetic peripheral neuropathic pain. Neuropsychiatr. Dis. Treat 11(1), 2101-2107 (2015).

69. Aiyer R, Barkin RL, Bhatia A. Treatment of Neuropathic Pain with Venlafaxine: A Systematic Review. Pain. Med 18(10), 19992012 (2017).

70. VanderWeide LA, Smith SM, Trinkley $K E$. A systematic review of the efficacy of venlafaxine for the treatment of fibromyalgia. J. Clin. Pharm. Ther 40(1), 1-6 (2015).

71. Karp JF, Butters MA, Begley AE, et al. Safety, tolerability, and clinical effect of low-dose buprenorphine for treatment-resistant depression in midlife and older adults. $J$. Clin. Psychiatry 75(8), e785-e793 (2014).
72. Fava M, Memisoglu A, Thase ME, et al. Opioid modulation with buprenorphine/ samidorphan as adjunctive treatment for inadequate response to antidepressants: a randomized double-blind placebocontrolled trial. Am. J. Psychiatry 173(5), 499-508 (2016).

73. Ahmadi J, Sefidfard Jahromi M. Ultrarapid Influence of Buprenorphine on Major Depression in Opioid-Dependent Patients: A Double Blind, Randomized Clinical Trial. Subst. Use. Misuse (2017).

74. Almatroudi A, Ostovar M, Bailey CP, et al. Antidepressant-like effects of BU10119, a novel buprenorphine analogue with mixed $\mathrm{K} / \mu$ receptor antagonist properties, in mice. Br. J. Pharmacol (2017).

75. Almatroudi A, Husbands SM, Bailey $\mathrm{CP}$, et al. Combined administration of buprenorphine and naltrexone produces antidepressant-like effects in mice. J. Psychopharmacol 29(7), 812-821 (2015).

76. Balon R. Buprenorphine for the treatment of depression? Acta. Psychiatr. Scand 134(1) 85-86 (2016).

77. Szkutnik-Fiedler D, Kus K, Balcerkiewicz $M$, et al. Concomitant use of tramadol and venlafaxine - evaluation of antidepressantlike activity and other behavioral effects in rats. Pharmacol. Rep 64(6), 1350-1358 (2012).

78. Barber J. Examining the use of tramadol hydrochloride as an antidepressant. Exp. Clin. Psychopharmacol 19(2), 123-130 (2011).

79. Chowta MN. Evaluation of role of noradrenergic system in the antidepressant effect of tramadol using tail suspension test in Albino mice. J. Pharmacol. Pharmacother 2(4), 281-282 (2011).

80. 80. Jesse CR, Wilhelm EA, Bortolatto CF, et al. Evidence for the involvement of the noradrenergic system, dopaminergic and imidazoline receptors in the antidepressant-like effect of tramadol in mice. Pharmacol. Biochem. Behav 95(3), 344350 (2010).

81. Faron-Górecka A, Kuśmider M, Inan SY, et al. Effects of tramadol on alpha2-adrenergic receptors in the rat brain. Brain. Res 1016(2), 263-267 (2004).

82. Faron-Górecka A, Kuśmider M, Inan SY, et al. Long-term exposure of rats to tramadol alters brain dopamine and $\mathrm{a}_{1}$ adrenoceptor function that may be related to antidepressant potency. Eur.J. Pharmacol 501(1-3), 103-110 (2004).

83. Rojas-Corrales MO, Berrocoso E, Mico JA. Role of 5-HT1 A and 5-HT1B receptors in the antinociceptive effect of tramadol. Eur. J. Pharmacol 511(1), 21-26 (2005).

84. Yalcin I, Coubard S, Bodard S, et al.
Effects of 5,7-dihydroxytryptamine lesion of the dorsal raphe nucleus on the antidepressant-like action of tramadol in the unpredictable chronic mild stress in mice. Psychopharmacology 200(4), 497-507 (2008).

85. Caspani O, Reitz MC, Ceci A, et al. Tramadol reduces anxiety-related and depressionassociated behaviors presumably induced by pain in the chronic constriction injury model of neuropathic pain in rats. Pharmacol. Biochem. Behav 124, 290-296 (2014).

86. Filip M, Wydra K, Inan SY, et al. Opioid and monoamine systems mediate the discriminative stimulus of tramadol in rats. Eur. J. Pharmacol 498(1-3), 143-151 (2004).

87. Miotto K, Cho AK, Khalil MA, et al. Trends in tramadol: pharmacology, metabolism, and misuse. Anesth. Analg 124(1), 44-51 (2017).

88. Jesse CR, Wilhelm EA, Barbosa NBV, et al. Involvement of different types of potassium channels in the antidepressant of tramadol in the mouse forced swimming test. Eur. J. Pharmacol 613(1-3), 74-78 (2009).

89. Szkutnik-Fiedler D, Kus K, Ratajczak P, et al. Coadministration of tramadol with aripiprazole and venlafaxine - the effect on spatial memory functions in male rats. Pharmacol. Rep 68(2), 451-456 (2016).

90. Zacny JP. Profiling the subjective, psychomotor, and physiological effects of tramadol in recreational drug users. Drug. Alcohol. Depend 80(2), 273-278 (2005).

91. Freye $E$, Levy JV. The effects of tramadol on pain relief, fast EEG-power spectrum and cognitive function in elderly patients with chronic osteoarthritis (OA). Acute. Pain 8(2), 55-61 (2006).

92. Kwok FJ, Yuen TS, Ng VM. A comparison of postoperative cognitive function and pain relief with fentanyl or tramadol patientcontrolled analgesia. J. Clin. Anesth 18(3), 205-210 (2006).

93. Mintzer MZ, Lanier RK, Lofwall MR, et al. Effects of repeated tramadol and morphine administration on psychomotor and cognitive performance in opioiddependent volunteers. Drug. Alcohol. Depend 111(3), 265-268 (2010).

94. Follet $M$, Lemoine $X$, Desbordes $M$, et al. Letter to the Editor (Case report). Tramadol improves catatonia: a case report. Prog. Neuropsychopharmacol. Biol. Psychiatry 32(8), 1996-1997 (2008).

95. Freye $E$, Levy JV. The effects of tramadol on pain relief, fast EEG-power spectrum and cognitive function in elderly patients with chronic osteoarthritis (OA). Acute. Pain 8(2), 55-61 (2006).

96. Kowalczyk M, Nowicka A, Antkowiak $B$, et al. Psychosomatic reactions to a 
Coexistence of Chronic Pain and Depression: A Short Review with a Focus on the Antidepressant Effect of RevieW Tramadol and Buprenorphine

stressful environment and an attempt at pharmacological modification. Med. Sci. Monit 7(5), 953-961 (2001).

97. Bassiony MM, Youssef UM, Hassan MS, et al. Cognitive Impairment and Tramadol Dependence. J. Clin. Psychopharmacol 37(1), 61-66 (2017).

98. Pergolizzi JV Jr, LeQuang JA, Berger GK, et al. The basic pharmacology of opioids informs the opioid discourse about misuse and abuse: a review. Pain. Ther 6(1), 1-16 (2017).

99. El-Hadidy MA, Helaly AM. Medical and psychiatric effects of long-term dependence on high dose of tramadol. Subst. Use. Misuse 50(5), 582-589 (2015).

100.Roussin A, Doazan-d'Ouince O, Géniaux H, et al. Evaluation of abuse and dependence in addiction monitoring systems: tramadol as an example. Therapie 70(2), 203-221 (2015).
101.Clinical guidelines for the use of buprenorphine in the treatment of opioid addiction. A treatment improvement protocol TIP 40. Consensus Panel Chair: McNicholas L. U.S. Department of Health and Human Services, Substance Abuse and Mental Health Services Administration, Center for Substance Abuse Treatment, USA (2004).

102.de Tommaso M, Arendt-Nielsen L, Defrin $\mathrm{R}$, et al. Pain in neurodegenerative disease: current knowledge and future perspectives. Behav. Neurol 7576292 (2016).

103. Dellarole A, Morton P, Brambilla R, et al. Neuropathic pain-induced depressive-like behavior and hippocampal neurogenesis and plasticity are dependent on tnfr1 signaling. Brain. Behav. Immun 41(1), 65-81 (2014).

104.104. Levin JM, Mendelson JH, Holman BL, et al. Improved regional cerebral blood flow in chronic cocaine polydrug users treated with buprenorphine. J. Nucl. Med 36, 1211-1215 (1995).

105.Murray DE, Durazzo TC, Schmidt TP, et al. Regional cerebral blood flow in opiate dependence relates to substance use and neuropsychological performance. Addict. Biol 12523 (2017).

106. Dhull DK, Kumar A. Tramadol ameliorates behavioural, biochemical, mitochondrial and histological alterations in ICV-STZ-induced sporadic dementia of Alzheimer's type in rats. Inflammopharmacology (2017).

107. Cruccu G, Truini A. A review of neuropathic pain: from guidelines to clinical practice. Pain. Ther 6(1), S35-S42 (2017).

108.Faria J, Barbosa J, Leal S, et al. Effective analgesic doses of tramadol or tapentadol induce brain, lung and heart toxicity in Wistar rats. Toxicology 385(1), 38-47 (2017) 